\title{
WHAT MAY AFFECT USERS TO SELL, BUY, OR SWAP ON WECHAT?
}

\author{
Linwu Gu, Indiana University of Pennsylvania, lgu@iup.edu \\ Jianfeng Wang, Indiana University of Pennsylvania,jwang@iup.edu
}

\begin{abstract}
Although previous research has explored the effects of different types of social network systems' impacts on individual and group shopping, researchers have focused little on how often a user sell, buy, and swap on WeChat. This article attempts to fill this void by examining WeChat exchange groups, through the task fit technology theory. The results, based on 167 questionnaires completed by two WeChat groups in USA, show that the perceived information-fit-totask and perceived relatedness positively affect IT-enabled collaboration capability. IT-enabled collaboration capability has positive consequences on user intention to sell, buy, and swap on WeChat.
\end{abstract}

Keywords: Task Fit Technology; Perceived Information Fit-To-Task; Collaboration Capability; User-To-User WeChat Exchange

\section{INTRODUCTION}

The growing influence of social media has driven increased attention to online communities (Schau, 2009). The task technology fit theory stipulates that perceived task technology fit determines an individual's performance (Goodhue and Thompson, 1995). In the academic literature, the effects of technology, task, and individual characteristics were studied on the outcomes under a wide variety of contexts. However, prior findings on the relationship between task characteristics and technology collaboration have been indecisive (Dennis and Valacich, 1994; Parboteeah, 2009). Zhang et al. (2015) examine the effects of perceived information fit-to-task and point out that the greater the perceived information fit-to-task, the greater the extent of the improvement in task-completing ability. IT-enabled collaboration compatibility can facilitate information and interaction on a team collaboration (Alsharo et al., 2017; Bala, 2016; Nambisan and Baron, 2009; and Pai, 2016). The growing influence of collaboration technology has prompted online communities, in which members obtain trade advice (Brown et al., 2007). The better an individual understands the benefits of a technology, the more effort that individual will make to use it (Sallberg and Bengtsson, 2016).

The perceived relatedness is a key factor for addressing collaboration and social interaction that can affect behavior. Previous literature has also found that different level of relatedness satisfies people with different level of job satisfaction (Li and Wang, 2017). Although researchers have made impressive progress in understanding online shopping behaviors, few scholars have investigated how the IT-enabled collaboration influence sell, buy, and swap on WeChat. Therefore, we argue that WeChat exchange groups can benefit from various mobile collaboration technology features because to sell, buy, swap on WeChat depends on the information fit-task and technology accessibility.

In this research, we seek to address the following research questions: 1) Do individual, technology and task characteristics have any impact on the perception of IT-enabled technology collaboration capability? 2) What role does IT-enabled collaboration capability play in the relationship between technology cognizance, perceived relatedness, and information fit-to-task and WeChat exchange? Drawing on task fit technology theory, we develop a research model to examine these questions. Next, we describe the methodology of the study and present the empirical results. The results suggest that to sell, buy, and swap on WeChat likely requires IT-enabled collaboration capability, to ensure successful transactions with immediate feedback and reviews. 


\section{MODEL AND CONSTRUCTS}

\section{Task Technology Fit Theory}

The theoretical model of task technology fit (Figure 1) shows us the task and individual characteristics have effects on task technology fit (Goodhue and Thompson, 1995). At its core, task technology fit theory offers insights on how the performance can be managed and maintained through the technology fit, which can lead to an effective outcome. Empirical findings on the topic have generally been consistent with the premise that task technology fit predicts actual usage behavior (Goodhue and Thompson, 1998).

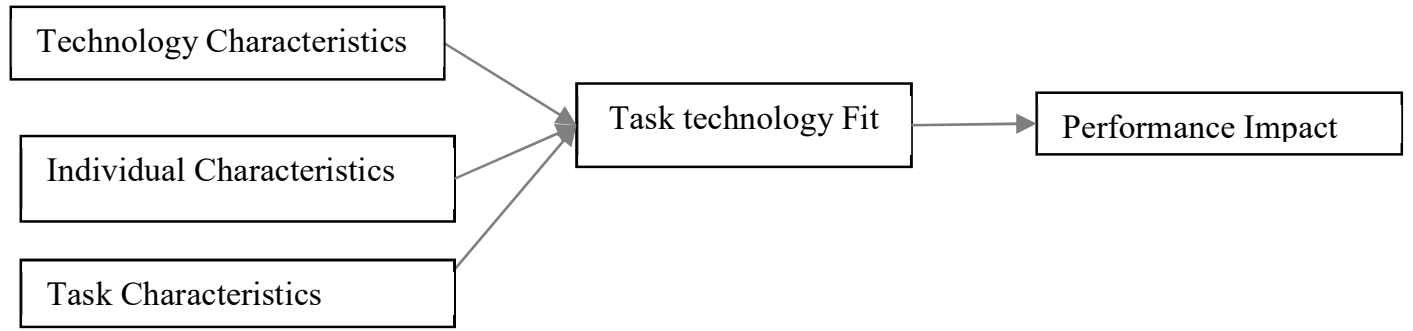

Figure 1. The Theoretical Model of TTF (Goodhue and Thompson, 1995)

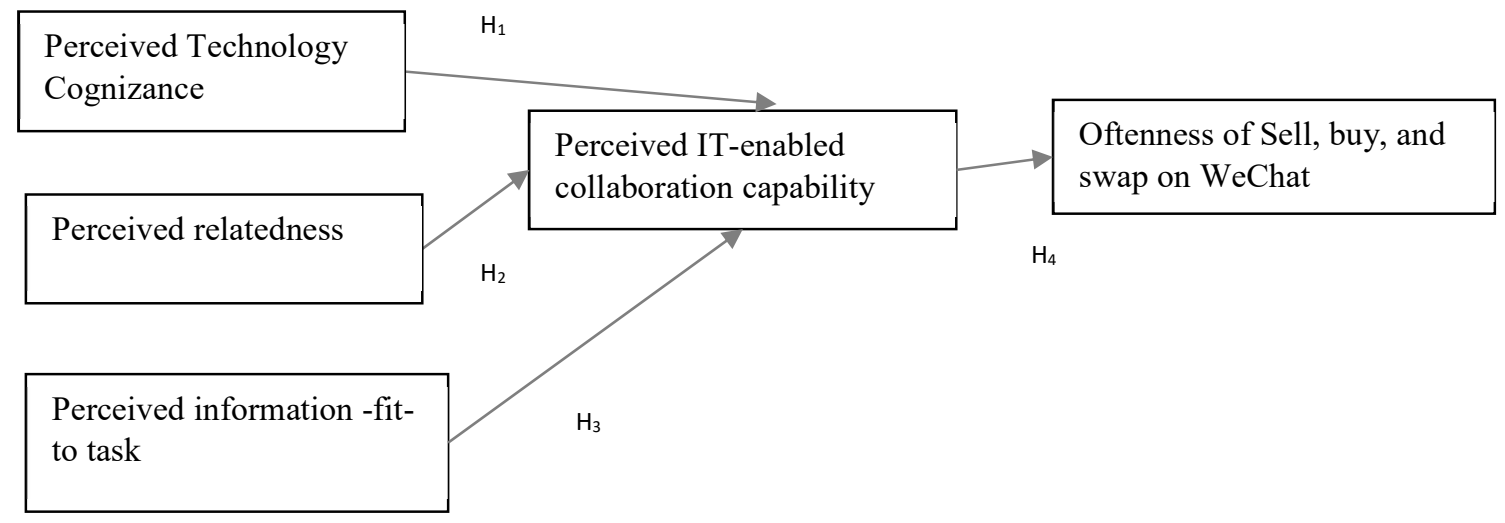

Figure 2. The Theoretical Model of IT-Enabled Collaboration Capability Impact on Perceived Oftenness to Sell, Buy, and Swap on WeChat

\section{IT-Enabled Collaboration Capability}

Bala (2016) defined IT-enabled collaboration capability as a user's evaluations of how well a collaboration technology supports behavior. Previous research also found that users develop positive perceptions of IT-enabled collaboration capability from their direct experience with the technology (Dennis and Fuller, 2008). Specifically, group members feel they can facilitate information processing, communicate effectively, reduce conflicts, and form interpersonal relationships successfully, when they use collaboration technology compatibly (Dennis and Valacich, 1994; Brown et al., 2010; McGrath, 1991; Jasperson, 2005).

\section{Technology Cognizance}

Perceived technology awareness determines an individual's intention to use technology (Davis, 1989; Taylor and Todd, 1995). Sallberg and Bengtsson (2016) assert that technology cognizance positively impacts the discovery and the different use of a technology. Technology awareness helps collaboration during virtual group settings (Pai and Tsai, 2016; Mark et al., 2001). We argue that more a WeChat user is aware of the features and capabilities of the 
WeChat technologies, higher the technology cognizance of the user, and therefore more willing the user will be to sell, buy, and swap on WeChat.

Given the discussion above, we developed the following hypothesis:

$\mathrm{H}_{1}$ : Perceived technology cognizance positively influences perceived IT-enabled collaboration capability.

\section{Perceived Relatedness}

Self-determination theory has been developed to understand how people's motivation leads to their subsequent behaviors. Explicitly, perceived relatedness, is defined as one's awareness of the degree to which he or she feels connected with others (Li and Wang, 2017; Menard et al., 2017). Empirical findings further indicate that perceived relatedness creates psychological ties that motivate to establish expectations of collaboration (Pai, 2016). Accordingly, perceived relatedness satisfies group work needs and makes members feel more like insiders than outsiders (Eisenberger et al., 1986).

Given the discussion above, we developed the following hypothesis:

$\mathrm{H}_{2}$ : Perceived relatedness positively influences perceived IT enabled collaboration capability.

\section{Information Fit-to-Task}

Task technology fit theory suggests that task characteristics play a serious role in motivating and enabling employees to explore the system $(\mathrm{Xu}, 2016)$. Although the literature in the management has identified various task characteristics, we focus on information fit-to-task. Information fit-to-task simplifies the fit between technology use and a task, the degree to which a system is compatible with the task's characteristics (Parboteeah et al., 2009). Users' perceived information fit-to-task would bring collaboration satisfaction and a hedonic experience. For example, if individuals find that the technology provides a high degree of benefits as related to their task, it is more likely that they will have a satisfactory affective reaction to the experience enabled by the technology (Zhang, 2015; Nambisan and Baron, 2009; Parboteeah et al., 2009).

Given the discussion above, we developed the following hypotheses:

$\mathrm{H}_{3}$ : Perceived information-fit-to-task positively influences perceived IT enabled collaboration capability.

$\mathrm{H}_{4}$ : Perceived IT enabled collaboration capability positively influences the perceived oftenness of sell, buy, and swap on WeChat.

\section{RESEARCH METHODOLOGY}

The purpose of our study is to understand the influences of these variables (Figure 2) on user-to-user exchange behavior through WeChat. Given the multidimensional nature of the study, structural equation modeling seems the most appropriate approach for assessing the hypotheses. Accordingly, each set of constructs was assessed for its measurement efficacy and then assessed as a collective network. Measures for the all the independent variables are based on the existing constructs that had been validated from the literature. All responses were based on a 7-point Likert scale ranging from strongly disagree to strongly agree (Appendix 1)

The sample of this study is from Two WeChat groups, whose users are all Chinese and mostly reside in the northeastern United States. We recruited $167 \mathrm{WeChat}$ users for this study: the average age of the applicants was 41.15 years; $92.3 \%$ are female. WeChat exchange groups, specific custom groups, have changed the way individuals communicate, interact, sell, buy, and swap on WeChat. It is the group member's decision to join an exchange topic group. If a member has no interests to sell, buy, and swap on WeChat, he/she can remove himself from the groups. The group leader can unilaterally remove a user within his/her group if the user does not follow the code of conduct of the group. WeChat Collaboration technology can be defined as feature-level use of an integrated collaboration platform. WeChat friendly interfaces enable exchange group members to have timely conversations with messages, photos, voice /videos calls that feature problem-solving, feedback and discussions for user-to-user exchanges.

We created a questionnaire with previously validated items for all the independent variables. Items for perceived relatedness was adopted from $\mathrm{Li}$ and Wang (2017). Items for perceived technology cognizance is adopted from Sallberg and Bengtsson (2016). Items for perceived information fit-to-task is adopted from Zhang et al. (2015). Items for perceived IT-enabled collaboration capability is adopted from Bella et al. (2017). We create one item for the dependent variable about the oftenness. The question for the oftenness is "how often do you sell, buy, and swap on 
WeChat?" Each of these items is measured on a 7-point Likert-type scale, from $1=$ strongly disagree to $7=$ strongly agree. The questionnaire is attached as the appendix (Appendix A).

\section{DATA COLLECTION AND ANALYSIS}

Data was collected from the two WeChat groups. One of the authors is a member in two WeChat exchange groups, spending lots of time chatting with group members on a daily or weekly basis for a couple of years. First, the author contacted the leader of each WeChat exchange group for a survey request within the group. Then, we posted the purpose, procedures, and the questionnaire webpage link to the participants to exchange WeChat group member. Within the following two weeks, participants accessed to our webpage to complete the questionnaire.

The Partial Least Squares (PLS) method performs a two-stage analysis using confirmatory factor analysis to assess the measurement model. Tables 1 and 2 display the measurement model analysis results. Reliability of the measurement model is assessed by examining internal consistency and reliability. Validity of the measurement model is assessed by discriminant validity. The square root of the AVE in the diagonal for each construct is higher than the inter-construct correlations on the same row and the same column as illustrated in Table 2. This suggests that the model has good discriminant validity.

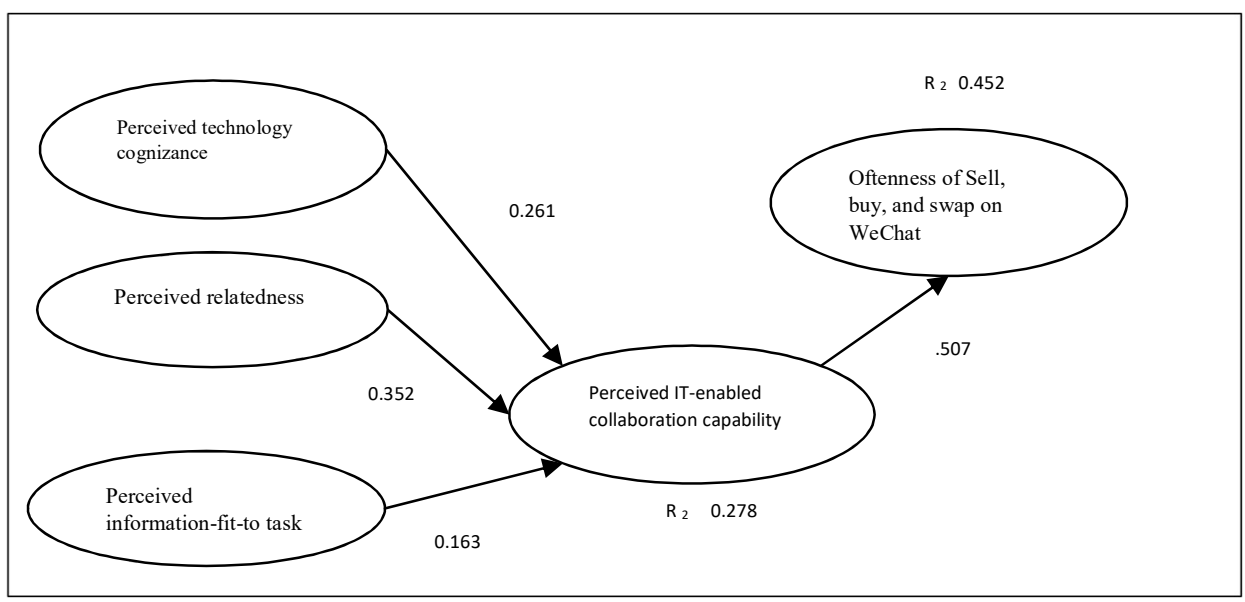

Figure 3. Path Diagram of the Results

Table 1. Descriptive Statistics, Constructs' AVE and Construct Reliability

\begin{tabular}{|l|c|c|c|c|}
\hline \multicolumn{1}{|c|}{ Constructs } & $\begin{array}{c}\text { Response } \\
\text { mean }\end{array}$ & $\begin{array}{c}\text { Standard } \\
\text { deviation }\end{array}$ & $\begin{array}{c}\text { Average } \\
\text { variance }\end{array}$ & $\begin{array}{c}\text { Construct } \\
\text { reliability }\end{array}$ \\
\hline Perceived IT -enabled collaboration capability & 4.4837 & 1.01 & 0.85 & 0.821 \\
Perceived relatedness & 5.1782 & 1.12 & 0.77 & 0.706 \\
Perceived information fit task & 4.1712 & 1.32 & 0.92 & 0.714 \\
Perceived technology cognizance & 4.9569 & 1.23 & 0.82 & 0.732 \\
Oftenness & 5.2431 & 1.42 & 0.75 & 0.843 \\
\hline
\end{tabular}

Table 2. Discriminant validity

\begin{tabular}{|l|l|l|l|l|l|l|}
\hline Construct & AVE & PIECC & PR & PIFT & PTC & O \\
\hline $\begin{array}{l}\text { Perceived IT-enabled collaboration } \\
\text { capability (PIECC) }\end{array}$ & 0.85 & 0.92 & & & & \\
\hline Perceived Relatedness (PR) & 0.77 & 0.72 & 0.88 & & & \\
\hline Perceived information-fit-task(PIFT) & 0.92 & 0.63 & 0.62 & 0.96 & & \\
\hline Perceived technology cognizance(PTC) & 0.82 & 0.59 & 0.52 & 0.41 & 0.91 & \\
\hline Oftenness (O) & 0.75 & 0.47 & 0.41 & 0.32 & 0.28 & 0.87 \\
\hline
\end{tabular}


Issues in Information Systems

Volume 19, Issue 2, pp. 155-162, 2018

Table 3. Model Coefficients and Significance

\begin{tabular}{|c|c|c|c|c|c|}
\hline $\begin{array}{l}\text { Dependent Variable: } \\
\text { Oftenness }\end{array}$ & $\mathrm{t}$ & $\mathrm{b}$ & $\mathrm{p}$ & $\mathrm{R}^{2}$ & Note \\
\hline & & & & 0.452 & \\
\hline Perceived IT enabled collaboration compatibility & 9.072 & 0.507 & .000 & & $\mathrm{H}_{4}$ supported \\
\hline \multirow{2}{*}{$\begin{array}{l}\text { Dependent Variable: } \\
\text { IT enabled collaboration compatibility }\end{array}$} & $\mathrm{t}$ & $\mathrm{b}$ & $\mathrm{p}$ & $\mathrm{R}^{2}$ & Note \\
\hline & & & & 0.278 & \\
\hline Perceived technology cognizance & 4.325 & 0.261 & .000 & & $\mathrm{H}_{1}$ supported \\
\hline Perceived relatedness & 2.485 & 0.352 & .007 & & $\mathrm{H}_{2}$ supported \\
\hline Perceived information fit-to-task & 2.124 & 0.163 & .018 & & $\mathrm{H}_{3}$ supported \\
\hline
\end{tabular}

Perceived relatedness $(\beta=0.352, p=0.007)$ has positive significant effects on perceived IT-enabled collaboration capability (Table 3). Many members of the two WeChat groups have known each other through shopping blogging sites before WeChat was available. They shared promotion and style information through the blogging sites and help each other in online shopping and exchange items they deemed as extra. When WeChat was available, they formed groups using WeChat and continued what they did before. WeChat features make things a lot easier to do. Our findings confirm Pai (2016), indicating that social ties are necessary for successful mobile collaboration. There is also a significant relationship between perceived technology cognizance and perceived IT-enabled collaboration capability $(\beta=0.261, p=0.000)$. When users know more of the features of WeChat systems, more confident they will be to use the tools, and more they will do to sell, buy, or swap through WeChat tools. Obviously, $\mathrm{H}_{1}$ and $\mathrm{H}_{2}$ are supported.

The significant relationship between perceived information-fit-task and perceived IT enabled collaboration capability was confirmed $(\beta=0.163, p=0.018)$. Any features through a system such as WeChat should be designed and developed to truly solve problems for users and meet their requirements and demands and expectations. WeChat tools turn out to be quite well on this standard. Perceived IT-enabled collaboration compatibility has a positive influence on the oftenness of buy, sell, and swap on WeChat is identified $(\beta=0.507, \mathrm{p}=0.000)$, significantly. Therefore, $\mathrm{H}_{3}$ and $\mathrm{H}_{4}$ are supported.

$\mathrm{R}^{2}$ at 0.278 is low. We believe there are other important factors we are not sure here, which have very important effects.

\section{CONCLUSIONS AND LIMITATIONS}

The results of this study offer several opportunities to user-to-user exchange business. We not only confirm the significant roles of mobile technology collaboration capability but also highlight the importance of managing technology, individual, and task focused drivers. The link between IT-enabled collaboration and exchange behavior appears depending on members' perception of information fit-to-task, which has several implications for IT technology managers. First, creating convenient mobile applications including peer-to-peer mobile payment is important to attract more and more mobile users ( $\mathrm{Gu}$ and Wang, 2017). Our results reveal that many participants appear interested in user-to-user exchanges with friendly collaboration tool. Successful user-to-user exchanges can be derived from effective interactions with mobile accomplished collaboration tools. Specifically, mobile features with multiple functions can enhance user interaction. Mobile collaboration technology can create valuable information, feedback and product reviews. To improve mobile user-to-user exchange application, IT technologies should provide a user-friendly infrastructure, efficient features, and peer-to-peer mobile payment.

The results of this study should be interpreted with caution for several reasons. First, our sample appears to have a gender bias, in that majority of the participants were female. Second, all group members are Chinese scholars or students in USA, who already have known each other a little bit through some blogging sites. The future research could explore the influence of culture on WeChat exchange behavior. Moreover, future research can provide greater insight into the impacts of user-to-user business in the theoretical model by considering richer variations of technology and task such as task variety, use of fear appeals, technology of privacy control, and so on. Although our study is a useful starting point, it is possible that the factors of WeChat exchange behaviors are influenced differently relative to different culture and different mobile applications. Accordingly, future research should be conducted as a comparative 
study to test our model with other user-to-user exchange groups in online community such as Facebook buy/sell/swap public groups.

\section{REFERENCES}

Alsharo, M., Gregg, D., \& Ramire, R. (2017). Virtual team effectiveness: The role of knowledge sharing and trust. Information \& Management, 54(4), 479-490.

Bala, H., Massey, A. \& Montoya, M. (2017). The Effects of Process Orientations on Collaboration Technology Use and Outcomes in Product Development. Journal of Management Information Systems, 34(2), 520-559.

Banker, R., Bardhan, I., \& Asdemir, O. (2006) Understanding the impact of collaboration software on product design and development. Information Systems Research, 17(4), 352-373.

Benlian, A., Titah, R., \& Hess, T. (2012). Differential effects of provider recommendations and consumer reviews in e-commerce transactions: an experimental study. Journal of Management Information System, 29(1), 237272.

Brown, J., Broderick, N., \& Lee, A. (2007). Word of mouth communication within online communities: conceptualizing the online social network, Journal of Interactive Marketing, 21(3), 2-20

Brown, S., Dennis, A., \& Venkatesh, V. (2010). Predicting collaboration technology use: Integrating technology adoption and collaboration research. Journal of Management Information Systems, 27(2), 9-53.

Davis, F. (1989). Perceived usefulness, perceived ease of use, and user acceptance of information technology. MIS Quarterly, 13(3), 319-339.

Dennis, A., \& Valacich, J. (1994). Group, sub-group and nominal group idea generation: New rules for a new media? Journal of Management, 20(4), 723-736.

Dennis, A., Fuller, R., \& Valacich, J. (2008). Media, Tasks, and Communication Processes: A Theory of Media Synchronicity. MIS Quarterly, 32(3), 575-600.

Dinev, T., Xu, H., Smith, J., \& Hart, P. (2013). Information Privacy and Correlates: An Empirical Attempt to Bridge and Distinguish Privacy-Related Concepts. European Journal of Information Systems, 22(3), 295-316.

Eisenberger, R., Huntington, R., Hutchison, S., \& Sowa, D. (1986). Perceived Organizational Support. Journal of Applied Psychology, 71(3), 500-507.

Goodhue, D. \& Thompson, R. (1995). Task-Technology Fit and Individual Performance. MIS Quarterly, 19(2), 213236.

Goodhue, D. \& Thompson, R. (1998). Development and Measurement Validity of a Task-Technology Fit Instrument for User Evaluations of Information Systems. Decision Sciences, 29(12), 105-138.

Hsu, C. \& Lin, C. (2018). Exploring Factors Affecting the Adoption of Internet of Things Services, Journal of Computer Information Systems, 58(1), 49-57.

Jasperson, J., Carter, P., \& Zmud, R. (2005). A Comprehensive Conceptualization of Post Adoptive Behaviors Associated with Information Technology Enabled Work Systems. MIS Quarterly, 29(3), 525-557.

Li Y, \& Wang X. (2017). Online Social Networking Sites Continuance Intention: A Model Comparison Approach. Journal of Computer Information Systems, 57(2), 160-168. 
Marks, M., Mathieu, J., \& Zaccaro, S. (2001). A Temporally Based Framework and Taxonomy of Team Processes. Academy of Management Review, 26(3), 356-376.

McGrath, J. (1991). Time, Interaction, and Performance (TIP): A Theory of Groups. Small Group Research, 22(2), $147-174$.

Menard, P, Bott, G, \& Crossler, R. (2017). User Motivations in Protecting Information Security: Protection Motivation Theory versus Self-Determination Theory. Journal of Management Information Systems, 34(4), 1203-1230.

Nambisan, S. \& Baron, R. (2009). Virtual Customer Environments: Testing a Model of Voluntary Participation in Value Co-Creation Activities. Journal of Product Innovation Management, 26(4), 388-406.

Pai, P. \& Tsai, H. (2016). Reciprocity Norms and Information-Sharing Behavior in Online Consumption Communities: An Empirical Investigation of Antecedents and Moderators. Information \& Management, $53(1), 38-52$.

Parboteeah, D., Valacich, J., \& Wells, J. (2009). The Influence of Website Characteristics on A Consumer's Urge to Buy Impulsively. Information System Research, 20(1), 60-78.

Sallberg, H., \& Bengtsson, L. (2016). Computer and Smartphone Continuance Intention: A Motivational Model. Journal of Computer Information Systems, 56(4), 321-330.

Schau, H., Muniz, A., \& Arnould, E. (2009). How Brand Community Practices Create Value. Journal of Marketing, $73(5), 30-51$.

Taylor, S., \& Todd, P. (1995). Understanding Information Technology Usage: A Test of Competing Models. Information System Research, 6(2), 144-176.

Xu, J. (2016). Retaining Customers by Utilizing Technology-Facilitated Chat: Mitigating Website Anxiety and Task Complexity. Information \& Management, 53(5), 554-569.

Zhang, H., Lu, Y., Wang, B., \& Wu, S. (2015). The Impacts of Technological Environments and Co-Creation Experiences on Customer Participation. Information \& Management, 52(4), 468-482.

\section{APPENDIX A}

IT-enabled collaboration capability (Bala et al., 2017):

1. I would rate the collaboration capabilities provided by WeChat high in terms of quality.

2. In general, WeChat provides me with high-quality collaboration capabilities. Collaboration satisfaction (reflective measures)

3. I am very satisfied with the collaboration capabilities provided by WeChat exchange group.

4. Overall, the collaboration capabilities provided by WeChat are very satisfying.

Perceived information fit-to-task (Modified from Zhang et al. (2015)):

1. The information on WeChat exchange is effective

2. The WeChat exchange group adequately meets my information needs

3. The WeChat exchange group is pretty much what I need to carry out my tasks

Technology Cognizance (adapted from Sallberg, H \& Bengtsson (2016)):

1. I have acquainted myself with, more or less, every feature of my smart phone

2. I know how to adjust the settings of my smart phone such that it works well for me

3. I know the most important technical strengths and weaknesses of my smart phone 
Relatedness (adapted from Li \& Wang (2017)):

1. I really like the people I interact with

2. I get along with people I come into contact with in

3. People are generally pretty friendly towards me in

4. The people I interact with regularly seem to like me much

Oftenness of Sell, buy, and swap on WeChat (Created by the authors $1=$ Never; $7=$ very often)

1. How often do you sell/buy/ swap on WeChat? 